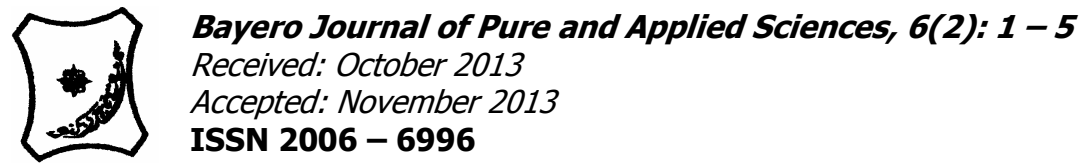

\title{
SPORTS/ENERGY DRINKS CONSUMPTION AMONG YOUNG ATHLETES IN KANO, NIGERIA
}

\author{
${ }^{* 1}$ Yunusa, I., ${ }^{1}$ Ahmad, I.M., ${ }^{2}$ Adegbusi, H.S., ${ }^{3}$ Abdulkadir, R.S., ${ }^{1}$ Huzaifa, U. and \\ ${ }^{4}$ Kabara, H.T. \\ ${ }^{1}$ Department of Biochemistry, Kano University of Science and Technology, Wudil. P.M.B. 3244, Kano. \\ ${ }^{2}$ Department of Computer Science, Katsina University, Katsina. P.M.B. 2137 \\ ${ }^{3}$ Department of Microbiology, Bayero University, Kano. P.M.B. 3011 Kano. \\ ${ }^{4}$ Department of Biochemistry, Bayero University, Kano. P.M.B. 3011 Kano. \\ *Correspondence author: isayunusa@yahoo.com
}

\section{ABSTRACT}

Little is known about the prevalence and motives of sport drinks use among adolescents and young adult athletes who exercise on regular basis in most football and other games pitches. Therefore, the current study was performed to assess information regarding the use of sport drinks among 440 athletes (23.5 \pm 4.62 years of age) in Kano Nigeria. Data were collected using a selfadministered, structured and pretested questionnaire. The results indicated that the frequency of sport drinks consumption was higher among male athletes and in those who did not have breakfast on a regular basis, ever smoked cigarettes and drank alcoholic beverages compared with their female counterparts. Athletes who had 'ever' tried a sport drink were significantly higher $(p<0.05)$ than those who had 'never' tasted the drink. Main reasons for using such drinks for regular users varied across the selected groups of athletes and included obtaining energy and boosting performance while doing sport. Most athletes claimed to be aware of the ingredients of sport drinks or their potential hazardous health effects, and that they could distinguish between sport and energy drinks. This study discovered that energy drinks were consumed by the athletes rather than sport drinks and that sport drinks are still alien to the study community as they are not commonly available in the market. This stands in strong contrast to the assumption that athletes consumed sport drinks. Therefore, increased awareness among the athletes of the discrepancies, ingredients and potential health hazards of both sport and energy drinks should be sustained.

Keywords: Sport drinks, consumption, adolescents, young adu/ts, athletes

INTRODUCTION

Sport drinks are beverages that may contain carbohydrates, minerals, electrolytes, and flavoring and are intended to replenish water and electrolytes lost through sweating during exercise (Committee on Nutrition and the Council on Sport Medicine and Fitness; CNCSMF, 2011). Sport drinks are useful for facilitating hydration, providing energy, and replacing electrolytes (National Academy of Sciences, 2007). The major benefits of commercial sport drinks are their prevention of hypohydration due to an increase in voluntary fluid intakes (Johnson et al., 1988). Sport drinks are a large and growing beverage industry now marketed to children and adolescents for a variety of uses. The growing interest coupled with youth exuberance in sporting activities indicated that they are definitely here to stay (Yunusa et al., 2012a). With children and adolescents, careful consideration is necessary when selecting a beverage to hydrate before, during, or after exercise and outside of physical activity to prevent excessive sugar and caloric intake that may encourage dental erosion, overweight, and obesity (American Academy of Pediatrics, Committee on Nutrition Sport Medicine, 2009). Pediatric athletes can benefit from using sport drinks that contain carbohydrates, protein, or electrolytes (Rodriguez et al., 2009); however, for the average child engaged in routine physical activity, the use of sport drinks in place of water on the sport field or in the school lunchroom is generally unnecessary (CNCSMF, 2011).

Physically active children and adolescents and their parents are often unaware of the additional nutrient and fluid needs relative to exercise. Sport drinks have an important, specific role in the diet of young athletes who are engaged in prolonged vigorous sport activity-primarily to rehydrate and replenish carbohydrate, electrolytes, and water lost during exercise (Rodriguez et al., 2009). The primary objectives of this study are to ascertain, for the first time, the level of consumption of sport drinks in Kano metropolis, and to understand the extent of misconception about energy by young people which can lead to unintentional ingestion of energy drinks when their goal is simply to rehydrate and replenish carbohydrate, electrolytes, and water with sport drinks.

\section{MATERIALS AND METHODS}

A cross-sectional study was conducted among adolescents and young adults athletes attending some selected foot ball and games pitches around Kano metropolis. Kano State occupies part of northern Nigeria. The global location of the State is between latitude $11^{0} 30^{\circ}$ north of the equator and between longitude $08^{0} 30^{\circ}$ east of the Greenwich Meridian (Wikipedia, 2012). 


\section{Sample Size}

The necessary sample size for the survey was derived using the following formula: $n=(4 \times p \times(100-p)) /$ 25 (Rainer et al., 1997). Where: $n=$ sample size, $p=$ expected prevalence of adolescents in developing countries (i.e., Nigeria). Therefore, $n=(4 \times 50 \times(100$ - 50)) / $25=400$; given a referenced 439 study participants from Attila and Çakir (2011).

\section{Data collection and inclusion criterion of} participants

Athletes from different locations attending game pitches were randomly selected and approached to be included in the study, if they agreed to participate. These subjects were likely to use sport drinks to boost their performance while exercising. The study included 440 participants; 324 males (73.6\%) and 116 female (26.4\%) from Kano metropolis. Data were collected via a self-administered, structured, pretested questionnaire. The questionnaire consisted of 12 questions on subjects' socio-demographic characteristics, education level, sport drinks-related knowledge, and consumption habits.

\section{Data analysis}

Statistical Package for Social Sciences (SPSS version 15.0 for Windows 2003) was used to calculate percentage distributions of socioeconomic status and education level, prior knowledge and consumption pattern. Students' T- test was used to compare between genders.

\section{RESULTS}

The study included 440 study participants, with ages from 16 to 35 years, with a mean \pm standard deviation of $23.5 \pm 4.62$ year (median 23.00 years). Distribution of age was quite homogenous across all athletes. Table 1 presents the distribution of sociodemographic characteristics of study participants. Of the group, 116 were female athletes (26.4\%) while 324 male constitute $73.6 \%$, but there was no significant difference $(P>0.05)$ between gender in terms of consumption rate. Most of the athletes interviewed 152 (34.5\%) reside within the ancient city of Kano, followed by those residing within the new lay-outs and Government Reserved Areas; GRAs (112; $25.5 \%$ and $92 ; 20.9 \%$ ) respectively. This pattern of residential settlement may account for the educational attainment of 204 (46.4\%) and 196 (44.5\%) for the secondary and tertiary levels for the athletes.

The study also investigated sport drinks use and related behavior among the study participants (Table 2). From the results, 304 athletes who have ever used sport drinks $(69.1 \%)$ were found to be significantly higher $(p<0.05)$ than those that never used sport drinks $124(28.7 \%)$, but this however, is not significantly associated ( $p>0.05$ ) with the type of game played. Athletes' main reason for using sport drinks was generally to get energy $176(40.0 \%)$, while $60(13.6 \%)$ wanted to boost performance while doing sport. More than half of the study participants 260 $(59.1 \%)$ consume sport drinks before breakfast, 36 $(8.2 \%)$ of the athletes drink along with cigarette smoke, whereas 8 athletes $(1.8 \%)$ reported that they consumed sport drinks mixed with alcohol.

Only 4 athletes $(0.9 \%)$ reported to consume the drinks before engaging in sporting activities. About the knowledge of ingredients contents of sport drinks, 176 athletes (40.0\%) reported that they were aware of the contents, while 120 athletes (27.3\%) were not aware. Athletes were asked to distinguish between energy and sport drinks; 196 (44.5\%) claimed to differentiate energy drinks from sport drinks, while 120 (27.3\%) could not distinguish between the two. Majority 170 $(40.0 \%)$ of the athletes claimed not to be aware of health hazards associated with sport drinks consumption, while $136 \quad(30.9 \%)$ responded otherwise.

Table 1: Distribution of socio-demographic characteristics of study participants $(n=440)$

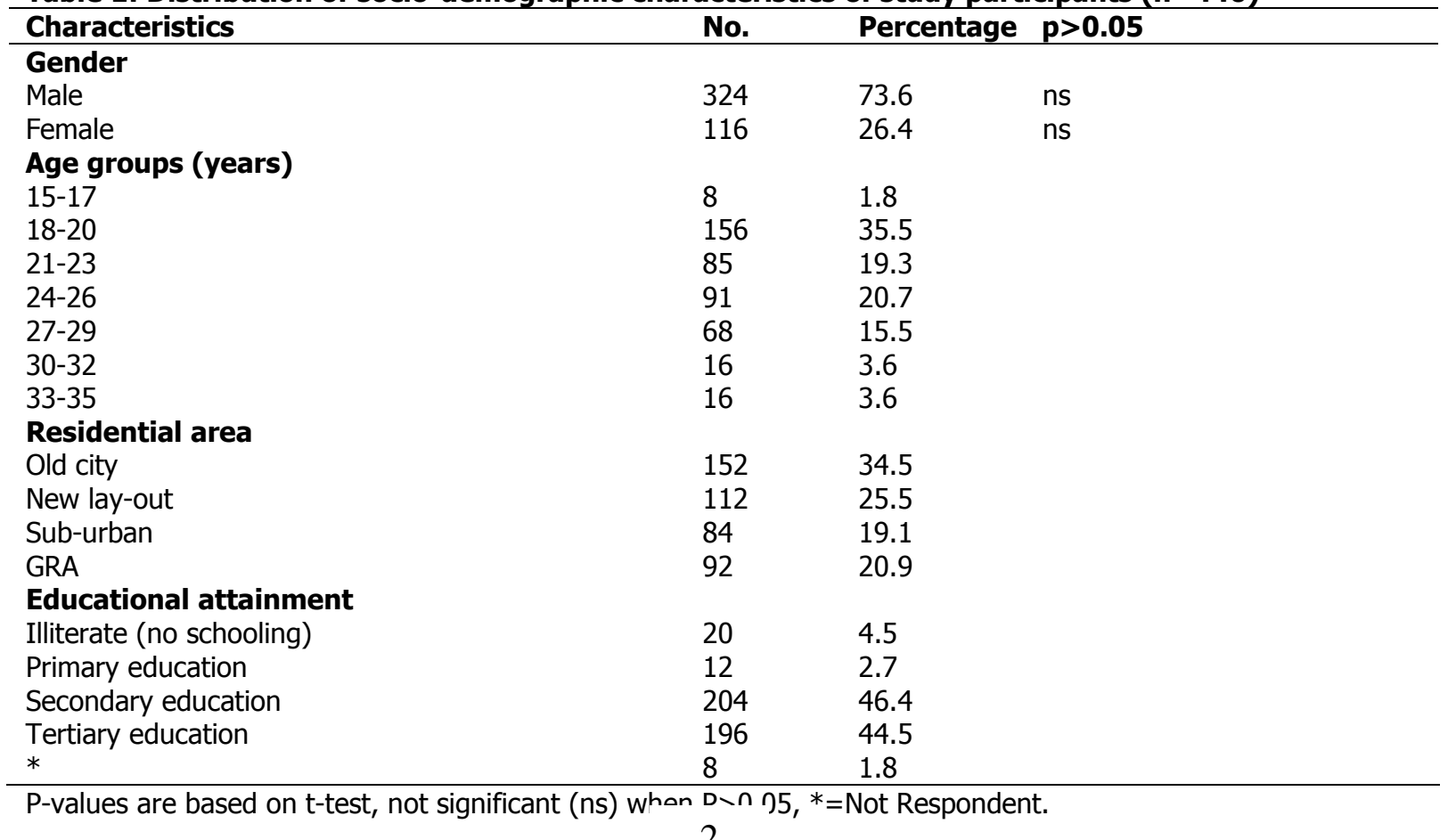


Bajopas Volume 6 Number 2 December, 2013

Table 2: Use of sport drinks and related behavior among study participants $(n=440)$

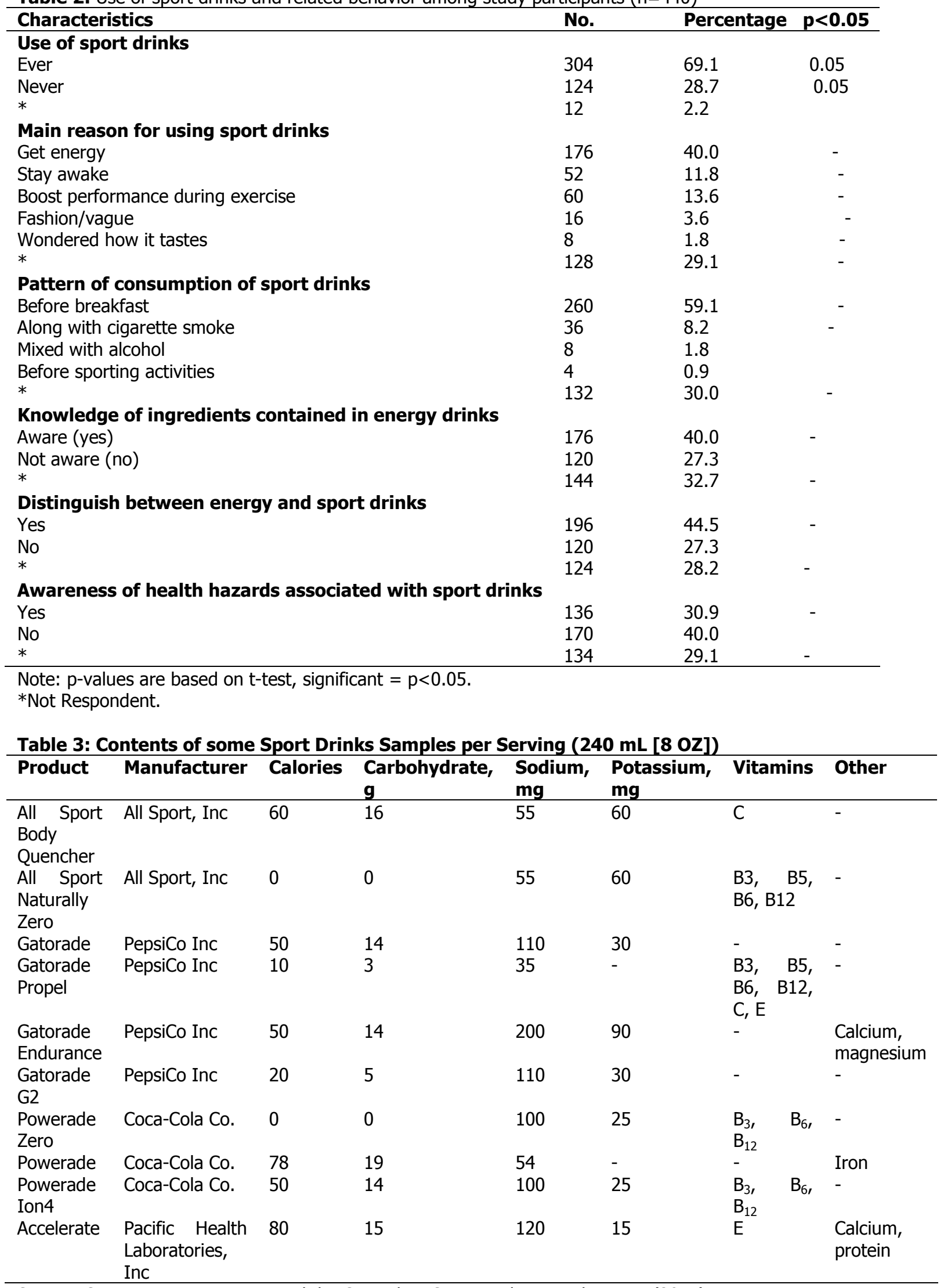

Source: Committee on Nutrition and the Council on Sport Medicine and Fitness (2011) 


\section{DISCUSSION}

In our study group, adolescents (aged 16-19 years) and young adults (aged 21-26 years) were the most prominent athletes. This corroborates with the findings that sport drink market is growing in size and adopting beverages that traditionally fit within other categories targeting a greater range of needs, ages and personalities (Spano, 2010) and most especially children and adolescents (Story and Klein, 2012). Also, the number of male athletes who participated was more than that of their female counterparts. Story and Klein (2012) earlier reported that adolescents, who consume sport drinks more than once a day, are more likely to be male. On the socioeconomic scale, majority of the athletes reside within the old city, followed by new lay-out settlements and GRAs. These could probably be the reason for higher number of those who attained secondary education against those who attained tertiary education (a surrogate for social stratification); also, Park et al. (2012) reported that adolescents who eat at fast-food restaurants more than once a week, and be physically inactive were more likely to consume sport drinks more than once a day, these indicators of socioeconomic status were positively correlated $(p<0.05)$ with sport drinks consumption among the athletes. This study indicated that the percentage of athletes who have 'ever' use sport drinks were more than those who have 'never' use the product. This high number of sport drinks users among the athletes could be as a result of increased social awareness; given that the increased consumption of sport drinks in recent years is of growing concern for parents, health professionals, and public health advocates (Story and Klein, 2012). The study also indicated that main reason for sport drinks consumptions among the study participants was to get energy and boost performance during sporting activities (Table 2). This supports the finding of O'Dea (2003). Although individual brands and products might vary, sport drinks typically contain nutrients such as water, electrolytes (primarily sodium and potassium), and carbohydrates (Snell et al., 2010). Carbohydrate options found in a number of popular sport drinks include high fructose corn syrup, fructose, sucrose syrup, brown rice syrup, cane juice, and maltodextrin (Manore et al., 2009). Depending on the brand, some sport drinks contain as much as 19 grams of added sugar, 200 milligrams of sodium, and 80 calories per 8 ounces (CNCSMF, 2011). These effects even make non-athletes - those who simply like the taste of sport drinks or who are looking for a different kind of beverage to patronize such drinks (Rouan, 2010).

The study also revealed the pattern of consumption of sport drinks, with almost half of the study participants consuming sport drinks before breakfast (Table 2). This could be as a result of their quest for energy; and in line with the findings of (Story and Klein, 2012). The habit of drinking along with cigarette smoke and mixing with alcohol was also observed among some athletes. Moreover, our study revealed that $45 \%$ of the study participants claimed to be aware of the ingredients contained in sport drinks and could be able to distinguish between energy from sport drinks. This agrees with the findings of Attila and Çakir (2011) and Yunusa et al. (2012b) who indicated most often energy drinks are not distinguished from "sport drinks".

According to the Committee on Nutrition and the Council on Sport Medicine and Fitness (2011), sport drinks are different products from energy drinks; therefore, the terms should not be used interchangeably. In the Joint Position Statement on Nutrition and Athletic performance published by the American College of Sport Medicine, American Dietetic Association, and Dietitians of Canada (2000), it is stated that consumption of sport drinks containing carbohydrates and electrolytes during exercise will provide fuel for the muscles, help maintain blood glucose and the thirst mechanism, and decrease the risk of dehydration or hyponatremia. They state that athletes will not need vitamin and mineral supplements if adequate energy to maintain body weight is consumed from a variety of foods. However, supplements will be required for athletes who restrict energy intake, use severe weight-loss practices, eliminate one or more food groups from their diet, or consume high-carbohydrate diets with low micronutrient density. It is noteworthy that the Joint Position Statement emphasizes that the nutritional ergogenic aids should be used with caution and only after careful evaluation of the product for safety, efficacy, potency, and whether or not it is a banned or illegal substance.

In addition, the study indicated that $30.9 \%$ of the athletes claimed to be aware of the health hazard associated with sport drinks consumption. These corroborate previous findings by Braun et al. (2009) that supplement use is common and widespread among German elite young athletes. The study also, revealed that athletes could not identify any one of those sport drinks they tried at least once when given a list of sport drinks from the manufacturers (Table 3). This was however confirmed by non-availability of the products from the local market after a cursory survey. These findings confirmed the confusion about energy by young people that can lead to unintentional ingestion of energy drinks when their goal is simply to rehydrate and replenish carbohydrate, electrolytes, and water with sport drinks (CNCSMF, 2011).

\section{Conclusion and Recommendations}

Energy drinks were consumed by the athletes instead of sport drinks and that consumption of energy drinks is quite common among athletes; particularly adolescents and young adults with a high socioeconomic status. Athletes were not aware of ingredients and potential health hazards, nor could they differentiate between such drinks. Therefore, parents, teachers, health educators, and media professionals should take responsibility to educate the public (youngsters, in particular) about the health hazards of sport and energy drinks and to increase motivation for a healthy diet. 


\section{REFERENCES}

American Academy of Pediatrics, Committee on Nutrition Sport medicine (2009): In: Kleinman RE, ed. Pediatric Nutrition Handbook. 6th ed. Elk Grove Village, IL: American Academy of Pediatrics. 225-239.

American College of Sport Medicine, American Dietetic Association, Dietitians of Canada. (2000): Joint position statement: nutrition and athletic performance.. Med. Sci. Sport Exerc. 32:2130-45.

Attila, S. and Çakir, B. (2011): Energy-drink consumption in college students and associated factors. Nutrition. 27: 316-322.

Braun, H., Koehler, K., Geyer, H., Kleinert, J., Mester, J. and Schänzer, W. (2009): Dietary supplement use among elite young German athletes. International Journal of Sport Nutrition and Exercise Metabolism. 19 (1): 97-109.

Committee on Nutrition and the Council on Sport Medicine and Fitness (2011): Sport drinks and energy drinks for children and adolescents: Are they appropriate? Pediatrics. 127(6):1182-1189.

Johnson, H.L., Nelson, R.A. and Consolazio, C.F.(1988): Effects of electrolyte and nutrient solutions on performance and metabolic balance. Med Sci Sport Exerc. 20(1):26-33

Manore, M.M., Meyer, N.L. and Thompson, J. (2009): Sport Nutrition for Health and Performance. 2nd ed. Champaign, IL: Human Kinetics.

National Academy of sciences (2007): Nutrition Standards for Foods in Schools: Leading the way toward healthier youth. In: http://www.nap.edu/catalog/11899.html.

O'Dea J.A.(2003): Consumption of nutritional supplements among adolescents: Usage and perceived benefits. Health Educ Res.18(1):98.

Park, S., Blanck, H.M., Sherry, B., Brener, N. and O'Toole, T. (2012): Factors associated with sugar-sweetened beverage intake among
United States high school students. J Nutr. 142(2):306-312.

Rainer, G., Arnfried, K., Hans, S. and Werner, S.(1997): Sample Size Guidelines for Nutrition Baseline Surveys in Communities. Version 1(2): 3.1.1.6. Jakarta. www.nutrisurvey.de/baseline/part31.htm

Rodriguez, N. R., DiMarco, N. M. and Langley, S.(2009): American Dietetic Association; Dietitians of Canada; American College of Sport Medicine. Position of the American Dietetic Association, Dietitians of Canada, and American College of Sport Medicine: nutrition and athletic performance. J. Am. Diet Assoc. 109(3):509 -527.

Rouan, R. (2010): Working out a new strategy-Sport drinks target serious athletes to rehydrate sales. Beverage Industry. 101(5):18-21.

Snell, P.G., Ward, R., Kandaswami, C. and Stohs, S.J. (2010): Comparative effects of selected noncaffeinated rehydration sport drink on shortterm performance following moderate dehydration. J. Int. Soc. Sport Nutr. 7:28.

Spano, M. (2010): Trends in sport drinks formulations. Prepared

Foods.

In:http://www.preparedfoods.com/articles/10 8306-trends-in-sport-drink-formulations

Story, M. and Klein, L. (2012): Consumption of Sport Drinks by Children and Adolescents. Healthy Eating Research. 1-7.

Yunusa, I., Gumel, M. A. and Ahmad, I. M. (2012a): Health Implications of Sport Drinks: A Review. Biological and Environmental Sciences Journal for the Tropics. 9 (3): 4245.

Yunusa, I. Gumel, M. A. and Ahmad, I. M.(2012b): Energy- drinks consumption among adolescents and young adults from Universities in Kano, Nigeria. Biological and Environmental Sciences Journal for the Tropics. 9 (1):34-38.

Wikipedia

(2012):

http://www.onlinenigeria.com/map.gif. In: http://en.wikipedia.org/wiki/Kano_State. 